\title{
EDITORIAL
}

\section{Resection of colonic lesions: full thickness, full monty?}

\author{
N. Pagano ${ }^{1}$
}

Received: 8 September 2019 / Accepted: 17 September 2019 / Published online: 9 October 2019

(c) Springer Nature Switzerland AG 2019

Resection of colonic lesions is the core business of gastrointestinal endoscopists in the Western world and a significant part of the workload for their counterparts in the East. Since the introduction of the technique of endoscopic mucosal resection (EMR), endoscopic treatment has experienced steady growth and shown signs of becoming the treatment of choice for colonic lesions. The advent of endoscopic submucosal dissection (ESD) has further reduced the rate of unresectable lesions, leading to a paradigm change in the East. The technique has rapidly spread to Western centers, with good results [1]. Nowadays, unless a lesion is invasive, endoscopy is considered the treatment of choice, at least to obtain a definitive diagnosis and staging. There has been an ongoing debate in the last decade about the role of ESD in the management of colonic lesions, and some evidence suggests that ESD is not superior to EMR [2, 3]. Nevertheless, for some lesions, there are technical issues that call for a more aggressive approach. In these cases, ESD often overcomes the limitations of EMR. From an oncological perspective, the current evidence suggests that when a superficial lesion invades the submucosa deeper than $1000 \mu \mathrm{m}$, the nodal risk is not negligible; therefore, in these cases, to avoid surgery, there is no advantage in using ESD rather than EMR. The technological development of the new fullthickness resection device (FTRD) system allows complete resection of the wall of the gastrointestinal tract, cutting and suturing in a one-step procedure [4]. This technique is a new tool in the endoscopist's armamentarium, and the evidence of its feasibility is accumulating. In the recent paper by Albrecht et al., a case series about the FTRD system showed good results in resecting non-lifting lesions of the colon with a high rate of R0 resection, nearly 90\% [5]. One's first impression is that resecting the full wall could increase oncological radicality: is it true? The literature shows that as

$\triangle$ N. Pagano

nicopagano@gmail.com

1 Gastroenterology Unit, Policlinico Sant'Orsola, Bologna, Italy regards histology, EMR is adequate for most colonic lesions because the only situation in which ESD is superior to EMR is in well-differentiated, slightly invasive lesions (SM1). En bloc resection allows a better histopathological evaluation so, we can conclude that resecting the full wall may be more effective, but we need to collect evidence to address this issue. At present, with available data, if a lesion invades the deep submucosal layer, even a full-thickness resection cannot change the nodal risk. It seems that we are in the same situation as with ESD: FTRD overcomes the technical limits of EMR but does not add much in terms of oncological radicality. We could argue that the FTRD technique is faster and easier, and this seems true in the per-protocol series, with a high rate of technical success [6]. An intention-to-treat study would be nearer to real life, considering the difficulties in reaching the lesion. Some conditions, like diverticulosis or a fixed colon, can impair the results of FTRD because the system is an over-the-scope one, with a large and rigid hood that increases the difficulty in advancing the scope. The paper by Albrecht is, so far, the nearest to clinical practice, but we still need more solid evidence. FTRD shows promising results also for submucosal lesions, like gastrointestinal stromal tumors or neuroendocrine tumors, which, until recently, have been an indication for surgery. In published series, about $15 \%$ of the resected lesions were submucosal with an R0 resection rate of up to $100 \%$ [5, 7]. We must consider that submucosal lesions, especially in the colon, are not so frequent and, then again, even a full-thickness resection does not change the risk of nodal involvement. Long-term results will provide information about the efficacy of FTRD in this setting. FTRD seems to have its best shot in the setting of residual or relapsing lesions or on scars, being, conceptually, the ideal treatment for these cases. Furthermore, on scars, EMR is often not feasible, and ESD is usually quite difficult, risky, and time-consuming. Lesions on a scar are less elastic, and this may decrease the size of the resected area even using FTRD, representing a limit in achieving R0 histology. For the 52 non-lifting benign lesions that included previously snared polyps, Albrecht and colleague report a 100\% $\mathrm{R} 0$ resection rate with mean size of the resected lesions of 
$19 \times 23 \mathrm{~mm}$. However, non-lifting lesions and scar lesions should be grouped in the same category; moreover, in published series, there is a reduction in the $\mathrm{R} 0$ resection rate of FTRD when the lesion size is over $2 \mathrm{~cm}$, including non-scar lesions [5-7]. Another issue that we need to clarify is the risk of complications of this new technique. When a technique spreads in the real world, there is usually a decrease in efficacy and an increase in the complication rate. According to Albrecht et al., the FTRD technique is associated with a complication rate of about $15 \%$, higher than that of EMR [5]. Of course, considering that the cases treated were the "difficult" ones, the rate of complications seems acceptable or, at least, understandable. The real conundrum here is the definition of "difficult" when we address a colonic lesion. Many efforts have been made to achieve standardization, but we are still far from an accepted definition [8]. What is difficult for one endoscopist may not be so for another who is more experienced. In this process, even traditions at different institutions as well as cultural background can make a difference $[9,10]$. Novelty is appealing, and, in the absence of objective criteria, the endoscopist might be more prone to offer the new option to the patient. So, what is considered a difficult lesion in retrospective series does not always coincide with the difficult real-world lesion. For these reasons, it is desirable to implement a new level of evidence, alongside a new standardized definition of the lesions, to obtain clearer results that could be more easily translated into clinical practice. These considerations apply the same to FTRD as to every new technique that will be proposed in the future.

\section{Compliance with ethical standards}

Conflict of interest The author declares that he has no conflict of interest.

Ethical approval This article does not contain any studies with human participants or animal performed by any of the authors.

Informed consent For this type of study formal consent is not required. a systematic review. Endoscopy 44(2):137-150. https://doi. org/10.1055/s-0031-1291448 (Epub 2012 Jan 23)

2. Arezzo A, Passera R, Marchese N, Galloro G, Manta R, Cirocchi R (2016) Systematic review and meta-analysis of endoscopic submucosal dissection vs endoscopic mucosal resection for colorectal lesions. United Eur Gastroenterol J 4(1):18-29. https://doi. org/10.1177/2050640615585470 (Epub 2015 May 5)

3. Fuccio L, Repici A, Hassan C, Ponchon T, Bhandari P, Jover R, Triantafyllou K, Mandolesi D, Frazzoni L, Bellisario C, Bazzoli F, Sharma P, Rösch T, Rex DK (2018) Why attempt en bloc resection of non-pedunculated colorectal adenomas? A systematic review of the prevalence of superficial submucosal invasive cancer after endoscopic submucosal dissection. Gut. 67(8):1464-1474. https ://doi.org/10.1136/gutjnl-2017-315103 (Epub 2017 Dec 5)

4. Schurr MO, Baur F, Ho CN, Anhoeck G, Kratt T, Gottwald T (2011) Endoluminal full-thickness resection of GI lesions: a new device and technique. Minim Invasive Ther Allied Technol 20(3):189-192. https://doi.org/10.3109/13645706.2011.582119 (Epub 2011 May 16)

5. Albrecht H, Raithel M, Braun A, Nagel A, Stegmaier A, Utpatel K, Schäfer C (2019) Endoscopic full-thickness resection (EFTR) in the lower gastrointestinal tract. Tech Coloproctol. https://doi. org/10.1007/s10151-019-02043-5 (Epub ahead of print)

6. Vitali F, Naegel A, Siebler J, Neurath MF, Rath T (2018) Endoscopic full-thickness resection with an over-the-scope clip device (FTRD) in the colorectum: results from a university tertiary referral center. Endosc Int Open. 6(1):E98-E103. https://doi. org/10.1055/s-0043-124079 (Epub 2018 Jan 16)

7. Schmidt A, Beyna T, Schumacher B, Meining A, Richter-Schrag HJ, Messmann H, Neuhaus H, Albers D, Birk M, Thimme R, Probst A, Faehndrich M, Frieling T, Goetz M, Riecken B, Caca K (2018) Colonoscopic full-thickness resection using an over-thescope device: a prospective multicentre study in various indications. Gut 67(7):1280-1289. https://doi.org/10.1136/gutjnl-2016313677 (Epub 2017 Aug 10)

8. Tholoor S, Tsagkournis O, Basford P, Bhandari P (2013) Managing difficult polyps: techniques and pitfalls. Ann Gastroenterol. 26(2):114-121

9. Buchner AM, Guarner-Argente C, Ginsberg GG (2012) Outcomes of EMR of defiant colorectal lesions directed to an endoscopy referral center. Gastrointest Endosc 76(2):255-263. https://doi. org/10.1016/j.gie.2012.02.060 (Epub 2012 May 31)

10. Luigiano C, Iabichino G, Pagano N, Eusebi LH, Miraglia S, Judica A, Alibrandi A, Virgilio C (2015) For, "difficult" benign colorectal lesions referred to surgical resection a second opinion by an experienced endoscopist is mandatory: a single centre experience. World J Gastrointest Endosc. 7(9):881-888. https://doi. org/10.4253/wjge.v7.i9.881

Publisher's Note Springer Nature remains neutral with regard to jurisdictional claims in published maps and institutional affiliations.

\section{References}

1. Repici A, Hassan C, De Paula Pessoa D, Pagano N, Arezzo A, Zullo A, Lorenzetti R, Marmo R (2012) Efficacy and safety of endoscopic submucosal dissection for colorectal neoplasia: 